\title{
Equilibrium and Kinetic Characteristics of Uranium Recovery by the Strong Base Ambersep 920U Cl Resin
}

\author{
Mohamed F. Cheira ${ }^{1}$, Akram M. El-Didamony ${ }^{2}$, Khalid F. Mahmoud ${ }^{3}$, \\ Bahig M. Atia ${ }^{4}$ \\ ${ }^{2}$ (Chemistry department, Faculty of Science, Zagazig University, Egypt) \\ 1, 3,4 (Nuclear Materials Authority, P.O. Box 530 El Maadi, Cairo, Egypt)
}

\begin{abstract}
The equilibrium and kinetic characteristics of the strong base macroreticular resin, Ambersep $920 U$ Cl developed by Rhom and Hass for uranium (VI) adsorption from high saline solutions have been determined using a synthetic uranium solution. The adsorption parameters including $\mathrm{pH}$, contact time, initial uranium (VI) concentration, temperature, diverse ions and chloride concentration have been optimized. The physical parameters including the adsorption kinetics, the isotherm models and the thermodynamic data have also been determined to describe the nature of the uranium (VI) adsorption by the working resin Ambersep $920 \mathrm{U} C$. The adsorption capacity of uranium (VI) upon the latter under the optimum conditions has been found to attain $50 \mathrm{mg} / \mathrm{g}$. Almost complete desorption of the adsorbed uranium (VI) has successfully been achieved with either $1 \mathrm{M} \mathrm{H}_{2} \mathrm{SO}_{4}$ acid solution or else with $0.6 \mathrm{M} \mathrm{Na}_{2} \mathrm{CO}_{3}$ solution. The realized capacity of the working resin has been found to agree with both the pseudo second order reaction and the Langmuir isotherm.
\end{abstract}

Keywords: Ambersep $920 \mathrm{U}$ Cl, Uranium Recovery. Adsorption, Desorption.

\section{Introduction}

Uranium is one of the most important heavy metals because of its strategic importance in the energy field ${ }^{(1)}$. Traditional solvent extraction processes which require extensive amounts of organic solvents have been a basic method of uranium concentration ${ }^{(2)}$. This technique has often been referred to as being tedious and time consuming. A special attention is actually focused on those techniques which are characterized by a considerable reduction or complete elimination of organic solvents ${ }^{(3,4)}$. Among these techniques, solid-liquid extraction has proved to be more advantageous in view of their total insolubility of the applied solid in the aqueous phase, its low rate of physical degradation besides its high sorption capacity as well as its good flexibility and kinetic properties ${ }^{(5,6)}$. Many types of adsorbents have been synthesized and studied for the recovery and separation of uranium (VI) such as Alizaren Red-S modified anion exchange resin ${ }^{(7)}$, a copolymer composed of acrylic acid (AA) and 2-acrylamide-2-methylpropane sulfonic acid (AMPS) crosslinked with N,Nmethylene bisacryl amide ${ }^{(8)}$ and crosslinked acrylic acid (AA) acrylonitrile (AN) copolymer resin ${ }^{(9)}$. A survey of the concerned literature indicates that uranium (VI) can be adsorbed as both the anionic complex species $\left[\mathrm{UO}_{2}\left(\mathrm{SO}_{4}\right)_{2}{ }^{2-}\right]$ and $\left[\mathrm{UO}_{2}\left(\mathrm{SO}_{4}\right)_{3}{ }^{4}\right]$ by a strong base anion exchange resin or else as a uranyl cation $\mathrm{UO}_{2}{ }^{2+}$ by a chelating ion exchange resin. Uranium (VI) adsorption using the low cost citrus biomass at $\mathrm{pH} 4^{\left({ }^{(1)}\right)}$ and Amberlite XAD-2 impregnated with cyanex-272 from the ore tailings of the complex oxide mineral uranmicrolite has given an uptake capacity of $41.76 \mathrm{mg} / \mathrm{g}^{(11)}$. The enrichment of uranium (VI) from monazite and the certified samples (USGS and GSP-1) by the chelating resin Amberlite XAD-2-orthovanillinthiosemicarbazone has also been studied ${ }^{(12)}$. In addition, the sorption of uranium from $\mathrm{HNO}_{3}$ acid using TBP-impregnated activated carbon was studied to optimize the experimental adsorption conditions ${ }^{(13)}$. The $\mathrm{pH}$ plays an important role on the uranium (VI) adsorption by oxidized activated carbon and chitosan ${ }^{(14)}$. A commercial phosphonic acid resin, Tulsion CH-96 was also used to extract uranium (VI) from $4 \mathrm{M} \mathrm{HNO}_{3}$ acid medium with an uptake capacity of $70 \mathrm{mg} / \mathrm{g}^{(15)}$. Natural clays as zeolites ${ }^{(16)}$ and manganese oxide coated sand ${ }^{(17)}$ are also used to adsorb $\mathrm{UO}_{2}{ }^{2+}$ from different matrices. Amberlite XAD-16 modified by bis-2-hydroxy benzyl-pphenylene diamine (BHBPD) has indeed been used as a selective chelating resin for preconcentration of uranium $(\mathrm{VI})^{(18)}$. A novel chelating resin, chloromethylated resin modified with thenoyl trifluoroacetone (TTA), was also applied for uranium (VI) selective adsorption with a maximum loading capacity of $138 \mathrm{mmol} / \mathrm{g}^{(19)}$. Also, uranium (VI) could be adsorbed using silica modified with both the xylenol orange of a loading capacity of $10 \mathrm{mg} / \mathrm{g}^{(20)}$ and the new class of multi dentate ligand anchored with polymeric resin by grafting Amberlite XAD-16 with [2-(methyl-3-oxo-2-phenyl-2,3-dihydro-1H-pyrazolyl-4-carbamoyl)-ethyl]-phosphonic acid abbreviated as (AXAD-16-MOPPA) and which has a loading capacity of $1.45 \mathrm{mmol} / \mathrm{g}^{(21)}$. In the light of the above discussion, the present work in concerned with the determination of the equilibrium and kinetic characteristics as well as the interesting thermodynamic data of the strong base, Ambersep $920 \mathrm{U} \mathrm{Cl}$ developed by Rhom and Hass for uranium (VI) recovery from high saline solutions using a synthetic uranium solution. This study has been found necessary to face such problems in all constituents where the mini Pilot Plant 
processing the uraniferous Abu Zeneima ore material of South Western Sinai is suffering from using a conventional anion exchange resin. This situation has implied a prior through washing of the ore material to eliminate most of the chloride species; a matter which otherwise would increase the production cost besides possible losses of some uranium. To realize the objectives of this work, the various parameters of uranium (VI) adsorption upon the studied resin have experimentally been optimized as a pre-requisite for the determination of the relevant physical characteristics.

\section{Ambersep 920U Cl Preparation:}

\section{Experimental}

The strong base industrial grade Ambersep 920 $\mathrm{Cl}$ ion exchange resin of Rohm and Haas is essentially a macroreticular anion exchange resin that has been used in the present work to determine its equilibrium and kinetic characteristics for uranium (VI) recovery from a synthetic solution. It is actually a true macroporous network which differs completely from the conventional gel type resins and which provides an outstanding osmotic and physical stability as well as excellent kinetics. It was purchased from Across Organics and prior application, it was washed with distilled water followed by $0.5 \mathrm{M}$ sulfuric acid for several times in turn and was then dried at $50^{\circ} \mathrm{C}$.

\section{Synthetic stock solutions:}

A standard stock solution of $1000 \mathrm{mg} / \mathrm{L}$ uranium (VI) has been prepared by dissolving $1.782 \mathrm{~g}$ of uranyl acetate dihydrate $\mathrm{UO}_{2}\left(\mathrm{CH}_{3} \mathrm{COO}\right)_{2} \cdot 2 \mathrm{H}_{2} \mathrm{O}$ (Prolabo) in $1000 \mathrm{ml}$ distilled water acidified with $2 \mathrm{ml}$ conc. sulfuric acid. On the other hand, several standard stock solutions of $1000 \mathrm{mg} / \mathrm{L}$ of possible interfering ions during U (VI) adsorption by the studied resin have been prepared by dissolving suitable weights of their salts in $1000 \mathrm{ml}$ distilled water.

\section{Experimental procedure:}

The batch procedure was performed to optimize the basic equilibrium conditions for uranium (VI) adsorption such as $\mathrm{pH}$, contact time, initial uranium concentration, temperature and diverse ion tolerance. In these experiments, $50 \mathrm{ml}$ of $150 \mathrm{mg} / \mathrm{L}$ uranium standard solution were mechanically mixed by stirring at $100 \mathrm{rpm}$ with $0.1 \mathrm{~g}$ resin into a $100 \mathrm{ml}$ conical flask. The mixture was shaken for a definite period of time at different temperatures. The amount of uranium adsorption $\mathrm{q}_{\mathrm{e}}(\mathrm{mg} / \mathrm{g})$ was calculated from the difference of uranium concentration in the aqueous solution before and after adsorption at the equilibrium time $\mathrm{t}$ according to the following equation:

$$
q_{e}=\frac{\left(C_{\circ}-C_{e}\right) V}{W}
$$

where $\mathrm{C}_{0}$ and $\mathrm{C}_{\mathrm{e}}$ are the liquid phase concentrations of uranium (VI) at initial and equilibrium time, respectively; $\mathrm{V}$ is the volume of the solution $(\mathrm{L})$ and $\mathrm{W}$ is the mass of dry resin used $(\mathrm{g})^{(22)}$. For the uranium desorption, different acids, alkalis and salts were studied as eluants for the adsorbed uranium (VI). Each experiment was performed by shaking $0.1 \mathrm{~g}$ of uranium-loaded resin with $5 \mathrm{ml}$ of each individual eluant at different concentration for 60 minute contact time at room temperature.

\section{Analytical procedures:}

The quantitative analysis of uranium was carried out by a single beam spectrophotometer, Meterch Inc (SP-8001) using Arsenazo III indicator (Sigma-Aldrich) ${ }^{(23)}$ and confirmed by an oxidimetric titration against ammonium metavanadate using N-phenyl anthranilic acid indicator (Sigma-Aldrich) ${ }^{(24,25)}$ using the computerized titrator, SCHOTT instruments, GmbH, Germany. The latter was also used for the quantitative analysis of chloride ions by titration using the silver nitrate method ${ }^{(26)}$.

The Inductively Coupled Plasma-Optical Emission Spectrometry, ICP-OES (Prodigy high dispersion ICP, TExxLEDYNE - Leeman Labs USA) was used to determine the tolerance limits of interferences of the studied diverse ions.

\section{Optimization of uranium adsorption conditions: Effect of pH:}

III. Results And Discussion

The effect of $\mathrm{pH}$ on uranium uptake $(\mathrm{mg} / \mathrm{g}$ ) from the synthetic sulfate solution by Ambersep $920 \mathrm{U} \mathrm{Cl}$ resin was studied in the range from 0.5 to 5 and in the absence of chloride ions while the other parameters were kept constant at $0.1 \mathrm{~g}$ resin, $50 \mathrm{ml}$ acidic solution assaying $150 \mathrm{mg} / \mathrm{L} \mathrm{U}$ (VI) concentration for $3 \mathrm{~h}$ contact time at room temperature. From the obtained results shown in Fig. (1), it is clearly evident that uranium uptake by the Ambersep $920 \mathrm{U} \mathrm{Cl}$ resin has attained a maximum value of $50 \mathrm{mg} / \mathrm{g}$ at $\mathrm{pH}$ values ranging from 0.5 to 3.5 . 


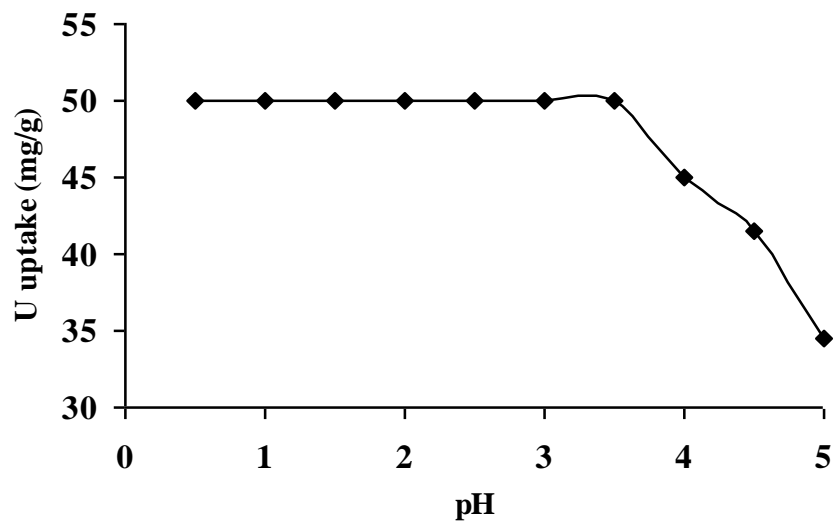

Figure (1): Effect of pH on uranium uptake using Ambersep 920U Cl.

(Extraction conditions: V: $50 \mathrm{ml}, \mathrm{C}_{0}: 150 \mathrm{mg} / \mathrm{L}(\mathrm{U}), \mathrm{W}: 0.1 \mathrm{~g}$ resin, $\mathrm{T}: 25^{\circ} \mathrm{C}$, contact time: 3 hours)

\section{Effect of contact time:}

The effect of contact time upon uranium uptake $(\mathrm{mg} / \mathrm{g})$ from $50 \mathrm{ml}$ of the synthetic chloride-free sulfate solution assaying $150 \mathrm{mg} \mathrm{U} / \mathrm{L}$ by Ambersep $920 \mathrm{U} \mathrm{Cl}$ resin was studied in the range of 10 to $210 \mathrm{~min}$. while the other extraction conditions were fixed at $\mathrm{pH} 2$ and using $0.1 \mathrm{~g}$ of the working resin at room temperature. The obtained results plotted in Fig. (2) indicate that the uranium uptake has gradually increased with increasing the contact time till reaching the maximum value of $50 \mathrm{mg} / \mathrm{g}$ at $90 \mathrm{~min}$. and remains constant thereafter. Hence, the adsorption equilibrium time considered for further work has been taken as $90 \mathrm{~min}$.

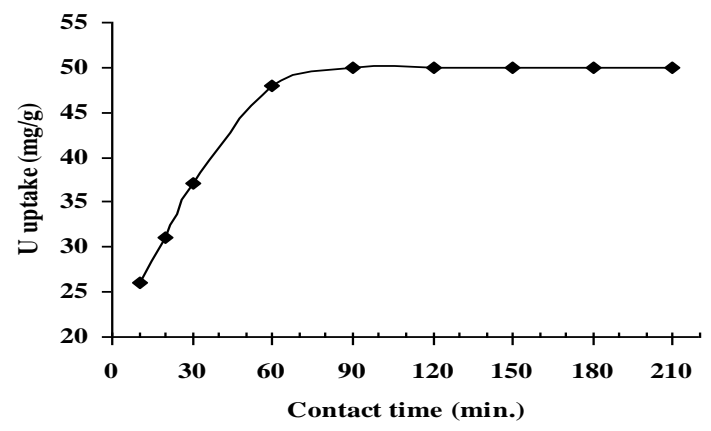

Figure (2): Effect of contact time on uranium uptake using Ambersep 920U Cl.

(Extraction conditions: $\mathrm{pH}: 2, \mathrm{~V}: 50 \mathrm{ml}, \mathrm{C}_{0}: 150 \mathrm{mg} / \mathrm{L}(\mathrm{U}), \mathrm{W}: 0.1 \mathrm{~g}$ resin, $\mathrm{T}: 25^{\circ} \mathrm{C}$ )

\section{Effect of initial uranium concentration:}

In absence of chloride ions, the effect of the initial uranium (VI) concentration on its adsorption upon $0.1 \mathrm{~g}$ of Ambersep $920 \mathrm{U} \mathrm{Cl}$ resin was studied in the range from 10 to $300 \mathrm{mg} / \mathrm{L}$ while the other factors were kept constant at $\mathrm{pH} 2$ for 90 min. contact time at room temperature. From the obtained data (Fig. 3), it is clear that the uranium uptake $(\mathrm{mg} / \mathrm{g})$ increases with increasing the uranium concentration till reaching the maximum uptake of uranium at $100 \mathrm{mg} / \mathrm{L}$ and which remains constant thereafter. Therefore, it can be ascertained that the maximum loading capacity of uranium upon Ambersep $920 \mathrm{U} \mathrm{Cl}$ resin is $50 \mathrm{mg} / \mathrm{g}$ equivalent to $50 \mathrm{~g} / \mathrm{Kg}$ resin.

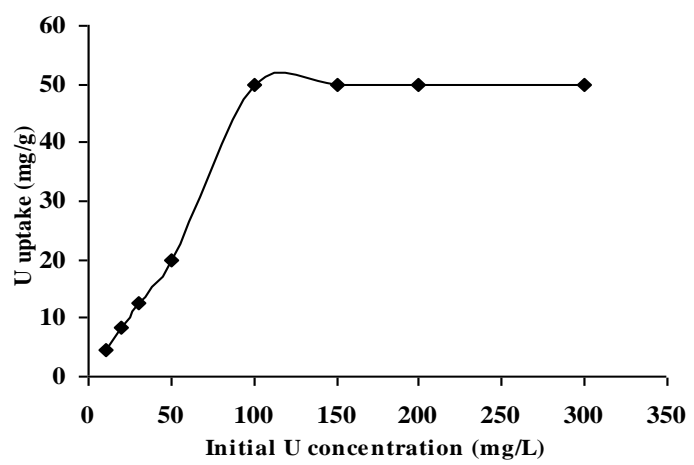

Figure (3): Effect of initial uranium concentration on uranium uptake using Ambersep 920U Cl. (Extraction conditions: $\mathrm{pH}: 2, \mathrm{~V}: 50 \mathrm{ml}, \mathrm{W}: 0.1 \mathrm{~g}$ resin, $\mathrm{T}: 25^{\circ} \mathrm{C}$, contact time: $90 \mathrm{~min}$.) 


\section{Effect of temperature:}

The effect of temperature on the uranium uptake capacity of $0.1 \mathrm{~g}$ Ambersep $920 \mathrm{U} \mathrm{Cl}$ resin from $50 \mathrm{ml}$ solution assaying $150 \mathrm{mg} / \mathrm{L}$ in the absence of chloride ions was studied within the temperature range of 25 to $60{ }^{\circ} \mathrm{C}$ while the other factors were kept constant at $\mathrm{pH} 2$ using $90 \mathrm{~min}$. contact time. From the obtained results represented in Fig. (4), it is clear that the uranium uptake capacity by the working resin has decreased with increasing the temperature indicating that the $\mathrm{U}(\mathrm{VI})$ adsorption is of an exothermic nature in a manner to be favored at room temperature. The uranium uptake capacity which at room temperature $\left(25^{\circ} \mathrm{C}\right)$ has attained $50 \mathrm{mg} / \mathrm{g}$ was decreased down to reach $31.5 \mathrm{mg} / \mathrm{g}$ at $60^{\circ} \mathrm{C}$. This decrease in the uranium uptake capacity with increasing temperature might be due to a decreasing effect in the surface activity where at higher temperature, the thickness of the boundary layer would decrease due to the increasing tendency of U (VI) to escape to the solution phase.

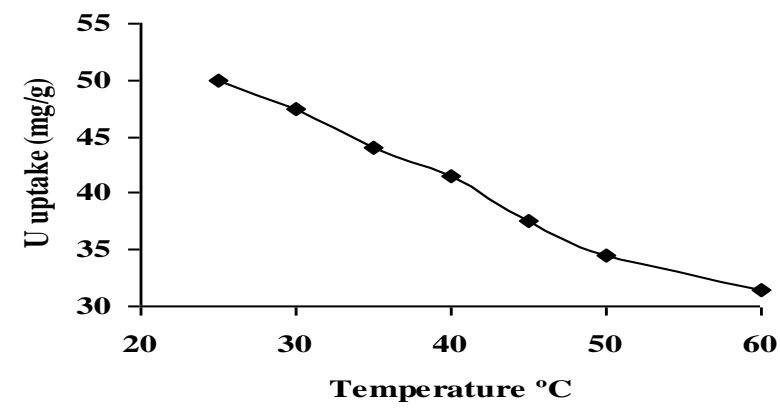

Figure (4): Effect of temperature on uranium uptake using Ambersep 920U Cl.

(Extraction conditions: $\mathrm{pH}: 2, \mathrm{~V}: 50 \mathrm{ml}, \mathrm{C}_{0}: 150 \mathrm{mg} / \mathrm{L}$ (U), W: $0.1 \mathrm{~g}$ resin, contact time: $90 \mathrm{~min}$.)

\section{Effect of interfering ions:}

The effect of other ions on the adsorption of U (VI) upon Ambersep 920U Cl was studied using different solution of a binary mixture of uranium (VI) with one of the other studied diverse ions under the optimized conditions. The results shown in Table (1) indicate that the working Ambersep $920 \mathrm{U} \mathrm{Cl}$ resin selectively adsorbs $\mathrm{U}(\mathrm{VI})$ in the presence of other diverse ions with an adequately high separation factor $\beta$ $\left(\beta=D_{u} / D_{m}\right)$ and a high tolerance limit. The $D_{U}$ and $D_{M}$ are the distribution ratio of uranium and the associated metal ion respectively.

Table (1): The effect of diverse ions on extraction of U (VI) using Ambersep 920U Cl.

\begin{tabular}{|c|c|c|c|c|c|c|c|}
\hline $\begin{array}{c}\text { Diverse } \\
\text { ions }\end{array}$ & $\begin{array}{c}\text { Tolerance } \\
\text { limit, W/W* }\end{array}$ & $\begin{array}{l}\% \text { U (VI) } \\
\text { Recovery }\end{array}$ & $\begin{array}{l}\text { Separation } \\
\text { factor, } \boldsymbol{\beta}^{* * *}\end{array}$ & $\begin{array}{c}\text { Diverse } \\
\text { ions }\end{array}$ & $\begin{array}{c}\text { Tolerance } \\
\text { limit, W/W* }\end{array}$ & $\begin{array}{l}\text { \% U (VI) } \\
\text { Recovery }\end{array}$ & $\begin{array}{l}\text { Separation } \\
\text { factor, } \boldsymbol{\beta}^{* *}\end{array}$ \\
\hline $\mathrm{Na}^{2+}$ & 2000 & 99 & $1 \times 10^{5}$ & $\mathrm{Cr}^{3+}$ & 300 & 99 & $1.6 \times 10^{5}$ \\
\hline $\mathbf{K}^{+}$ & 2000 & 99 & $1 \times 10^{5}$ & $\mathrm{Ni}^{2+}$ & 300 & 98 & $1.6 \times 10^{4}$ \\
\hline $\mathrm{Ca}^{2+}$ & 2000 & 99 & $1 \times 10^{5}$ & $\mathrm{Cu}^{2+}$ & 500 & 99 & $2.5 \times 10^{4}$ \\
\hline $\mathbf{M g}^{2+}$ & 2000 & 99 & $1 \times 10^{5}$ & $\mathrm{Zn}^{2+}$ & 300 & 98 & $1.6 \times 10^{4}$ \\
\hline $\mathrm{Si}^{4+}$ & 2000 & 99 & $1 \times 10^{5}$ & $\mathrm{Fe}^{3+}$ & 500 & 98 & $5 \times 10^{3}$ \\
\hline $\mathbf{A l}^{3+}$ & 2000 & 99 & $1 \times 10^{5}$ & $\mathrm{Zr}^{4+}$ & 250 & 98 & $1.2 \times 10^{4}$ \\
\hline $\mathrm{Ba}^{2+}$ & 2000 & 99 & $1 \times 10^{5}$ & $\mathbf{P b}^{2+}$ & 200 & 98 & $9.8 \times 10^{3}$ \\
\hline $\mathbf{P}^{5+}$ & 2000 & 99 & $1 \times 10^{5}$ & $\mathbf{V}^{5+}$ & 500 & 99 & $2.5 \times 10^{4}$ \\
\hline $\mathrm{Ti}^{4+}$ & 200 & 99 & $1 \times 10^{5}$ & $\mathrm{Mn}^{2+}$ & 300 & 99 & $1.6 \times 10^{4}$ \\
\hline
\end{tabular}

(Extraction conditions: $\mathrm{pH}: 2, \mathrm{~V}: 50 \mathrm{ml}, \mathrm{C}_{0}: 50 \mathrm{mg} / \mathrm{L}(\mathrm{U}), \mathrm{T}: 25^{\circ} \mathrm{C}, \mathrm{W}: 0.1 \mathrm{~g}$ resin, contact time: $\left.90 \mathrm{~min}.\right)$

* Weight ratio of the interfering ion to that of uranium (VI).

\section{Effect of chloride concentration:}

The effect of chloride ions on uranium (VI) adsorption by Ambersep $920 \mathrm{U} \mathrm{Cl}$ is very important. During uranium adsorption upon the traditional anion exchange resins, it was found that the chloride ions compete and substitute the anionic uranium complex species; hence a reduction of uranium uptake would be manifested. To overcome this problem, a modified resin structure was developed by Rhom and Hass; namely Ambersep 920U Cl resin which would selectively adsorb uranium ions in the presence of relatively high chloride ions concentration. Accordingly, it was found necessary to study the effect of chloride ions on the uranium adsorption of Ambersep 920 $\mathrm{U} \mathrm{Cl}$ resin within the concentration range from 1 upto $50 \mathrm{~g} / \mathrm{L}$ while the other factors were kept constant at the above mentioned optimum conditions but using $50 \mathrm{ml}$ solution assaying $50 \mathrm{mg} / \mathrm{L} \mathrm{U}$ (VI). From the obtained results, it is observed that a chloride concentration ranging from $1 \mathrm{go} 30 \mathrm{~g} / \mathrm{L}$ does not affect the uranium uptake capacity and which has slightly been decreased thereafter (Fig. 5). 


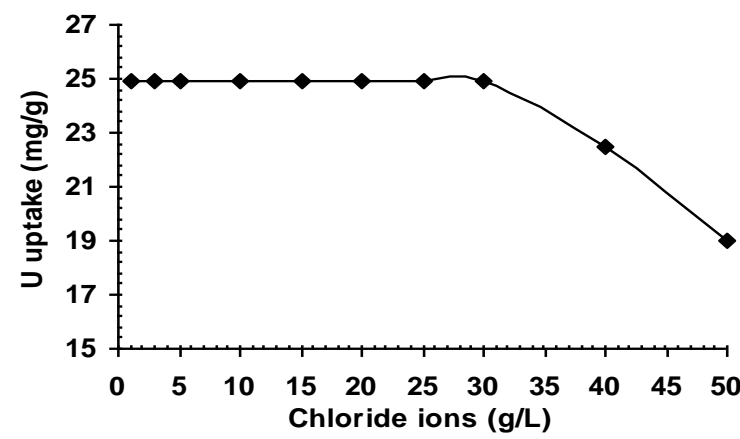

Figure (5): Effect of chloride concentration on uranium uptake using Ambersep 920U Cl.

(Extraction conditions: $\mathrm{pH}: 2, \mathrm{~V}: 50 \mathrm{ml}, \mathrm{C}_{0}: 50 \mathrm{mg} / \mathrm{L}(\mathrm{U}), \mathrm{T}: 25^{\circ} \mathrm{C}, \mathrm{W}: 0.1 \mathrm{~g}$ resin, contact time: $90 \mathrm{~min}$.)

\section{Characteristics of the physical parameters:}

Kinetic characteristics:

In order to investigate the kinetic characteristics concerning the mechanism of $\mathrm{U}(\mathrm{VI})$ adsorption upon Ambersep 920U Cl resin and the potential rate controlling steps such as mass transport, the pseudo-first order model and the pseudo-second order one were applied ${ }^{(27)}$. In the pseudo-first order equation:

$$
\log \left(q_{e}-q_{t}\right)=\log q_{e}-\left(\frac{K_{1}}{2.303}\right) t
$$

$\mathrm{q}_{\mathrm{e}}$ is the equilibrium adsorption capacity $(\mathrm{mg} / \mathrm{g})$, and $\mathrm{K}_{1}$ is the pseudo-first order rate constant (min. ${ }^{-1}$ ). The plot of $\log \left(\mathrm{q}_{\mathrm{t}}-\mathrm{q}_{\mathrm{e}}\right)$ against $\mathrm{t}$ gives a straight line plot as shown in Fig. (6), which suggests the applicability of the pseudo-first order kinetics model to fit the experimental data as given in Table (2). The calculated value of the adsorption capacity, $\mathrm{q}_{\mathrm{e}}$, cal. is $73.8 \mathrm{mg} / \mathrm{g}$ which is higher than the experimentally determined capacity of $50 \mathrm{mg} / \mathrm{g}$. On the other hand, in the pseudo-second order equation:

$$
\frac{t}{q_{t}}=\frac{1}{K_{2} q_{e}^{2}}+\left(\frac{1}{q_{e}}\right) t
$$

$\mathrm{K}_{2}$ is the rate constant of the pseudo-second order adsorption $\left(\mathrm{g}^{\mathrm{mg}} \mathrm{g}^{-1} \cdot \mathrm{min}^{-1}\right)$. The pseudo-second order plot of t/qt against $t$ is graphically plotted in Fig. (7) which is also linear and with a correlation coefficient of 0.9947. However the calculated value of the adsorption capacity, $\mathrm{q}_{\mathrm{e}, \mathrm{eal}}$, of $51.2 \mathrm{mg} / \mathrm{g}$ is closer to the experimentally determined capacity; namely $\mathrm{q}_{\mathrm{e}}$, exp. of $50 \mathrm{mg} / \mathrm{g}$. Therefore, it could be suggested that $\mathrm{U}$ (VI) adsorption by Ambersep $920 \mathrm{U} \mathrm{Cl}$ resin better follows the pseudo-second order model than the pseudo-first order model.

Table (2): Kinetic parameters of uranium adsorption on Ambersep 920U Cl.

\begin{tabular}{c|c|ccc|crr}
\hline Resin & Experimental & \multicolumn{3}{|c|}{ Pseudo-first order } & \multicolumn{3}{|c}{ Pseudo-second order } \\
\cline { 3 - 8 } & $\mathbf{q}_{\mathbf{e}, \text { exp. }}(\mathbf{m g} / \mathbf{g})$ & $\mathbf{q}_{\mathrm{e}}, \mathbf{m g} / \mathbf{g}$ & $\mathbf{K}_{\mathbf{1}}$ & $\mathbf{R}^{2}$ & $\mathbf{q}_{\mathrm{e}}, \mathbf{m g} / \mathbf{g}$ & $\mathbf{K}_{\mathbf{2}}$ & $\mathbf{R}^{2}$ \\
Ambersep 920U Cl & 50 & 73.8 & 0.068 & 0.9653 & 51.2 & 0.0025 & 0.9947 \\
\hline
\end{tabular}

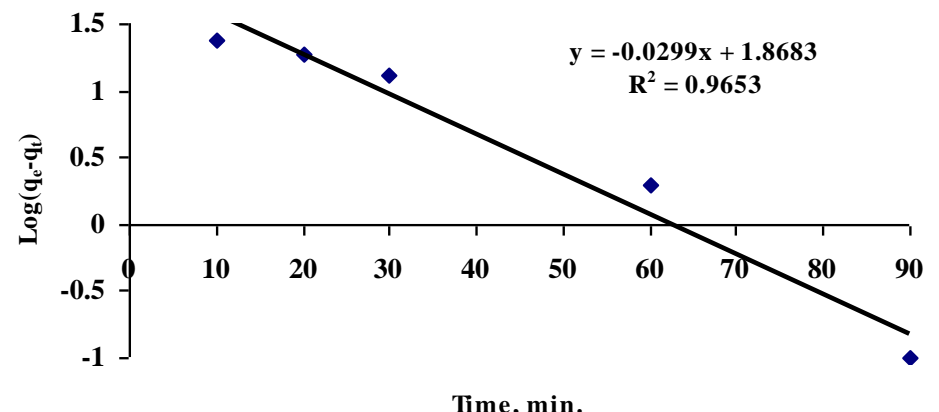

Figure (6): Pseudo-first order kinetics of uranium adsorption on Ambersep 920U Cl.

(Extraction conditions: $\mathrm{pH}: 2$, V: $50 \mathrm{ml}, \mathrm{C}_{0}: 150 \mathrm{mg} / \mathrm{L}(\mathrm{U}), \mathrm{W}: 0.1 \mathrm{~g}$ resin, $\mathrm{T}: 25^{\circ} \mathrm{C}$ ) 


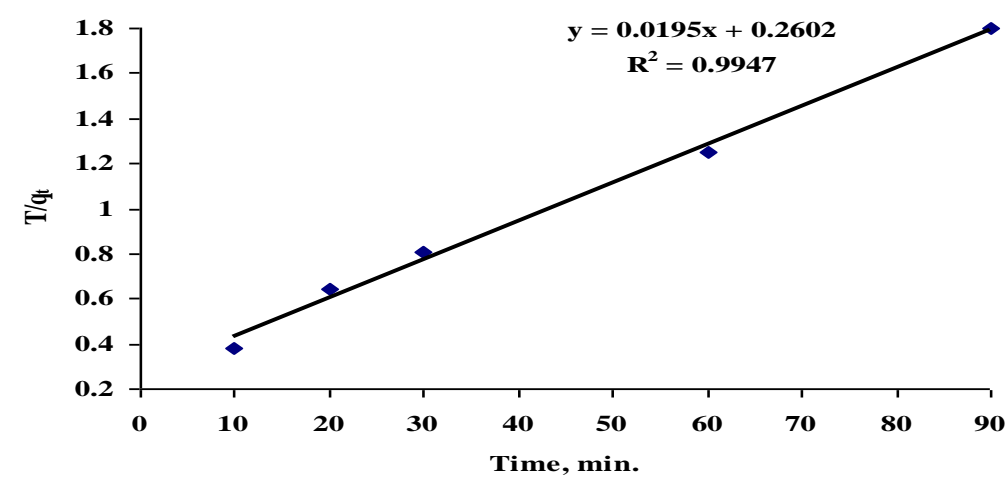

Figure (7): Pseudo-second order kinetics of uranium adsorption on Ambersep 920U Cl.

(Extraction conditions: $\mathrm{pH}: 2$, V: $50 \mathrm{ml}, \mathrm{C}_{0}: 150 \mathrm{mg} / \mathrm{L}(\mathrm{U}), \mathrm{W}: 0.1 \mathrm{~g}$ resin, $\mathrm{T}: 25^{\circ} \mathrm{C}$ )

\section{Isotherm models:}

The adsorption isotherm provides the most important information about how the adsorbed molecules are distributed between the solid and aqueous phases when the adsorption process reaches an equilibrium state. For this purpose, the uranium adsorption on Ambersep $920 \mathrm{U} \mathrm{Cl}$ has been described by applying the most widely used Langmuir ${ }^{(28)}$ and Freundlich isotherm ${ }^{(29)}$ models. The Langmuir isotherm considers the adsorption as a chemical phenomenon with the formation of energetically mono layer with a maximum adsorption capacity of $\mathrm{q}_{\max }(\mathrm{mg} / \mathrm{g})$ through the following equation:

$$
\frac{C_{e}}{q_{e}}=\frac{C_{e}}{q_{\max }}+\frac{1}{K_{L} q_{\max }}
$$

where $\mathrm{K}_{\mathrm{L}}$ is a constant of the adsorption equilibrium $(\mathrm{L} / \mathrm{mg}), \mathrm{q}_{\max }$ is the saturated monolayer adsorption capacity ( $\mathrm{mg} / \mathrm{g}$ ) while $\mathrm{q}_{\mathrm{e}}$ and $\mathrm{C}_{\mathrm{e}}$ are the uranium uptake capacity $(\mathrm{mg} / \mathrm{g}$ ) of adsorbent and the residual uranium concentration (mg/L) at equilibrium. A linearized plot of $\mathrm{C}_{\mathrm{e}} / \mathrm{q}_{\mathrm{e}}$ against $\mathrm{C}_{\mathrm{e}}$ gives $\mathrm{q}_{\max }$ and $\mathrm{K}_{\mathrm{L}}$ is shown in Fig. (8). On the other hand, in the empirical Freundlich equation based on adsorption on heterogenous surface:

$$
\log _{e}=\log K_{f}+\frac{1}{n} \log C_{e}
$$

$\mathrm{K}_{\mathrm{F}}$ and $\mathrm{n}$ are the Freundlich constants which represent the adsorption capacity and the adsorption intensity respectively. $K_{F}$ and $n$ can be determined from a linear plot of Log $q_{e}$ against $\log C_{e}$ (Fig. 9). The results of the Langmuir and Freundlich isotherm constants are given in Table (3) where it is found that uranium (VI) adsorption on Ambersep $920 \mathrm{U} \mathrm{Cl}$ correlates quite well $\left(\mathrm{R}^{2}>0.99\right)$ with the Langmuir equation as compared with the Freundlich equation under the studied concentration range. Langmuir model is thus suitable for the description of the adsorption equilibrium of uranium (VI) onto Ambersep 920U Cl. The essential characteristics of the Langmuir isotherm can be expressed in terms of a dimensionless constant separation factor ${ }^{(30)}, R_{L}$, which is used to predict if an adsorption system is favorable or not. The separation factor, $\mathrm{R}_{\mathrm{L}}$, is given by the following equation:

$$
R_{L}=\frac{1}{1+K_{L} C_{0}}
$$

where $\mathrm{C}_{0}$ is the initial uranium (VI) concentration $(\mathrm{mg} / \mathrm{L})$ and $\mathrm{K}_{\mathrm{L}}$ is the Langmuir adsorption constant $\left(\mathrm{L} / \mathrm{mg}\right.$ ). Table (4) lists the calculated results of the $\mathrm{R}_{\mathrm{L}}$ values for uranium (VI) concentration ranging from 10 to $300 \mathrm{mg} / \mathrm{L}$. Based on the effect of separation factor on the isotherm shape, the $R_{\mathrm{L}}$ values are in the range of $0<\mathrm{R}_{\mathrm{L}}<1$, which indicates that the adsorption of uranium (VI) on Ambersep $920 \mathrm{U} \mathrm{Cl}$ is favorable.

Table (3): Langmuir and Freundlich isotherm model constants for Ambersep 920U Cl resin.

\begin{tabular}{c|ccc|ccc}
\hline Practical capacity, $\mathrm{q}_{\mathrm{e}},(\mathrm{mg} / \mathrm{g})$ & \multicolumn{3}{|c|}{ Langmuir isotherm model } & \multicolumn{3}{c}{ Freundlich isotherm model } \\
\cline { 2 - 7 } & $\mathrm{q}_{\max }$ & $\mathrm{K}_{\mathrm{L}}$ & $\mathrm{R}^{2}$ & $\mathrm{q}_{\max }$ & $\mathrm{n}$ & $\mathrm{R}^{2}$ \\
50 & 54.3 & 0.077 & 0.995 & 5.03 & 2.013 & 0.947 \\
\hline
\end{tabular}


Table (4): $\mathbf{R}_{\mathrm{L}}$ values based on the Langmuir equation

\begin{tabular}{cc}
\hline $\mathbf{U}(\mathbf{V I}), \mathbf{m g} / \mathbf{L}$ & $\mathbf{R}_{\mathbf{L}}$ \\
\hline $\mathbf{1 0}$ & $\mathbf{0 . 5 8}$ \\
20 & $\mathbf{0 . 4 1}$ \\
30 & $\mathbf{0 . 3 2}$ \\
50 & $\mathbf{0 . 2 2}$ \\
100 & $\mathbf{0 . 1 2}$ \\
150 & $\mathbf{0 . 0 8}$ \\
200 & 0.06 \\
300 & 0.04 \\
\hline
\end{tabular}

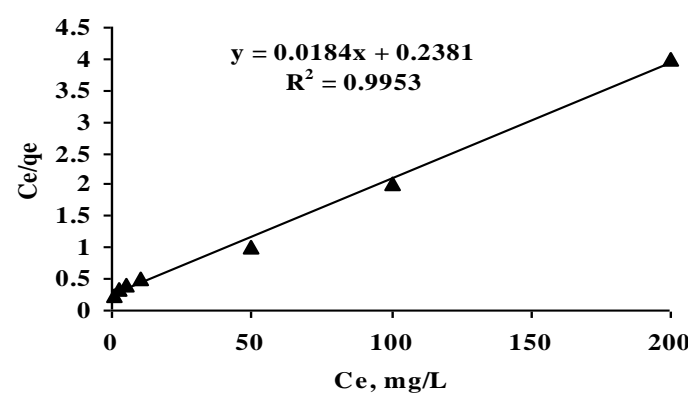

Figure (8): Langmuir adsorption isotherm model of U (VI) on Ambersep 920U Cl.

(Extraction conditions: pH: 2, V: $50 \mathrm{ml}, \mathrm{W}: 0.1 \mathrm{~g}$ resin, $\mathrm{T}: 25^{\circ} \mathrm{C}$, contact time: $90 \mathrm{~min}$.)

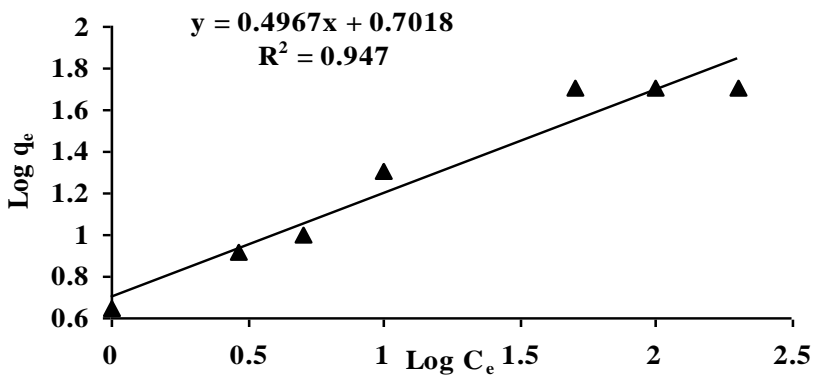

Figure (9): Freundlich adsorption isotherm model of U (VI) on Ambersep 920U Cl.

(Extraction conditions: $\mathrm{pH}: 2, \mathrm{~V}: 50 \mathrm{ml}, \mathrm{W}: 0.1 \mathrm{~g}$ resin, $\mathrm{T}: 25^{\circ} \mathrm{C}$, contact time: $90 \mathrm{~min}$.)

\section{Thermodynamic characteristics:}

The thermodynamic parameters of the studied adsorption process have been determined from a series of experiments carried out at various temperatures ranging from 25 to $60{ }^{\circ} \mathrm{C}$. These parameters were calculated for this system using the following Van't Hoff equation:

$$
\log K_{d}=\frac{\Delta S}{2.303 R}-\frac{\Delta H}{2.303 R T}
$$

where $\mathrm{K}_{\mathrm{d}}(\mathrm{ml} / \mathrm{g}), \Delta \mathrm{H}(\mathrm{KJ} / \mathrm{mol}), \Delta \mathrm{S}(\mathrm{KJ} / \mathrm{mol} . \mathrm{K}), \mathrm{T}(\mathrm{Kelvin})$ and $\mathrm{R}\left(\mathrm{J} \cdot \mathrm{K}^{-1} \cdot \mathrm{mol}^{-1}\right)$ are the distribution coefficient, the enthalpy, the entropy, the temperature in Kelvin and the molar gas constant respectively. The plot of $\log \mathrm{K}_{\mathrm{d}}$ against 1/T for uranium (VI) adsorption upon Ambersep 920U Cl is shown in Fig. (10). The values of $\Delta \mathrm{H}$ and $\Delta \mathrm{S}$ were obtained from the slope and intercept of the latter plot while the Gibbs free energy, $\Delta \mathrm{G}(\mathrm{KJ} / \mathrm{mol})$, is calculated from the following equation ${ }^{(31)}$ :

$$
\Delta \mathrm{G}=\Delta \mathrm{H}-\mathrm{T} \Delta \mathrm{S}
$$

The calculated values of the thermodynamic parameters for U (VI) adsorption on Ambersep $920 \mathrm{U} \mathrm{Cl}$ are given in Table (5). It was found that the negative value of $\Delta \mathrm{H}$ shows that $\mathrm{U}$ (VI) adsorption is of an exothermic nature whereas the negative numerical values of $\Delta \mathrm{G}$ which increase with increasing temperature indicating that the adsorption reaction is spontaneous. In addition, the negative $\Delta \mathrm{S}$ parameter suggests decreasing the system randomness at the solid-liquid interface during the adsorption process. 
Table (5): Thermodynamic parameters of uranium (VI) adsorption on Ambersep 920U Cl.

\begin{tabular}{|c|c|c|c|c|c|c|c|c|c|}
\hline \multirow[t]{2}{*}{ Resin } & \multirow{2}{*}{$\begin{array}{c}\Delta \mathbf{H} \\
\mathrm{KJ} / \mathrm{mol}\end{array}$} & \multirow{2}{*}{$\begin{array}{c}\Delta \mathbf{S} \\
\mathrm{KJ} / \mathrm{mol} . \mathrm{K}\end{array}$} & \multicolumn{7}{|c|}{$\Delta \mathbf{G}(\mathrm{KJ} / \mathrm{mol})$} \\
\hline & & & $298^{\circ} \mathrm{K}$ & $303^{\circ} \mathrm{K}$ & $308^{\circ} \mathrm{K}$ & $313^{\circ} \mathrm{K}$ & $318^{\circ} \mathrm{K}$ & $323^{\circ} \mathrm{K}$ & $333^{\circ} \mathrm{K}$ \\
\hline Ambersep 920U Cl & -26.14 & -0.03 & -17.2 & -17.05 & -16.9 & -16.75 & -16.6 & -16.45 & -16.15 \\
\hline
\end{tabular}

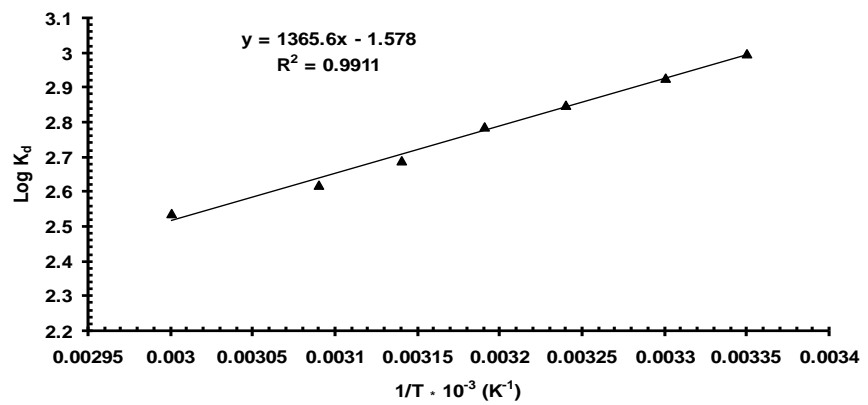

Figure (11): Effect of temperature on the thermodynamic behavior of uranium (VI) adsorption upon Ambersep 920U Cl.

(Extraction conditions: $\mathrm{pH}: 2, \mathrm{~V}: 50 \mathrm{ml}, \mathrm{C}: 150 \mathrm{mg} / \mathrm{L}, \mathrm{W}: 0.1 \mathrm{~g}$, contact time: $90 \mathrm{~min}$. )

\section{Uranium desorption characteristics:}

The desorption or the elution characteristics of uranium (VI) from the loaded Ambersep 920U Cl without removing the retained matrix components has been studied in the present work by several acid, alkali and salt solutions. Thus, various eluting agents including the acids $\left(\mathrm{HCl}, \mathrm{H}_{2} \mathrm{SO}_{4}\right.$ and $\left.\mathrm{HNO}_{3}\right)$, the alkalis $\left(\mathrm{Na}_{2} \mathrm{CO}_{3}\right.$ and $\left.\mathrm{NaHCO}_{3}\right)$, and the salts $\left(\mathrm{NaCl}, \mathrm{Na}_{2} \mathrm{SO}_{4}\right.$ and $\left.\mathrm{NH}_{4} \mathrm{NO}_{3}\right)$ in concentrations ranging from 0.2 to $3 \mathrm{M}$ have been applied. In these experiments, the other parameters were kept constant involving a $5 \mathrm{ml}$ volume of the eluant solution for 1 hour contact time at ambient temperature for $0.1 \mathrm{~g}$ uranium (VI)-loaded resin. From the obtained results plotted in Fig. (12), it was observed that the elution efficiencies of uranium (VI) ions have increased with increasing the concentration of the applied acids until reaching the maximum values of 84, 99.9 and $66 \%$ for $0.8 \mathrm{M} \mathrm{HCl}, 1 \mathrm{M} \mathrm{H}_{2} \mathrm{SO}_{4}$ and $0.6 \mathrm{M} \mathrm{HNO}_{3}$ respectively and above which the elution efficiencies have gradually decreased. In case of alkalis, the uranium (VI) elution efficiencies have increased with increasing their concentration until reaching the maximum values of 99.9 and $94 \%$ at $0.6 \mathrm{M}$ of either $\mathrm{Na}_{2} \mathrm{CO}_{3}$ or $\mathrm{NaHCO}_{3}$ respectively. Finally, the uranium (VI) elution efficiencies using the indicated salts have increased with increasing their concentration to obtain 72,58 and $92 \%$ at $1 \mathrm{M} \mathrm{NaCl}, 0.6 \mathrm{M} \mathrm{Na} \mathrm{SO}_{4}$ and $1 \mathrm{M} \mathrm{NH}_{4} \mathrm{NO}_{3}$ respectively. Hence, it can be concluded that $1 \mathrm{M} \mathrm{H}_{2} \mathrm{SO}_{4}$ or $0.6 \mathrm{M} \mathrm{Na}_{2} \mathrm{CO}_{3}$ can be used for almost quantitative desorption of uranium (VI) from the working Ambersep 920 $\mathrm{Cl}$ anion exchange resin.

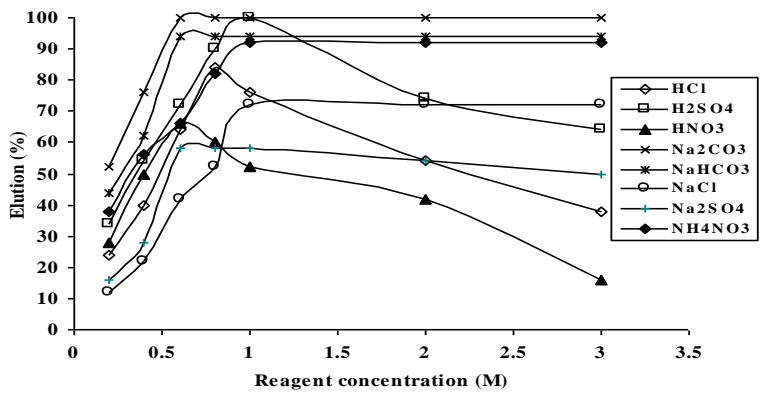

Figure (12): Effect of concentration of the different chemical reagents on uranium elution efficiency.

(Elution conditions: V: $5 \mathrm{ml}, \mathrm{T}: 25^{\circ} \mathrm{C}, \mathrm{W}: 0.1 \mathrm{~g}$ resin, contact time: $1 \mathrm{~h}$ )

\section{Conclusion}

The strong base Ambersep 920U Cl anion exchange resin developed for high saline solution was applied for uranium (VI) adsorption from a synthetic sulfate solution. The purpose was to determine both the optimum adsorption conditions and the equilibrium and kinetic characteristics. The obtained results indicate that uranium (VI) adsorption is strongly dependent on the $\mathrm{pH}$ of the aqueous solution and where under the optimum conditions a maximum adsorption of $50 \mathrm{mg} / \mathrm{g}$ resin was obtained at $\mathrm{pH} 2$ for $90 \mathrm{~min}$. shaking time of $0.1 \mathrm{~g}$ resin in $50 \mathrm{ml}$ of the synthetic solution assaying $150 \mathrm{mg} / \mathrm{L}$ uranium at room temperature. Referring to the theoretical 
capacity of the working resin of $1 \mathrm{eq} / 1 \mathrm{~L}$ resin, it can be indicated that this would correspond to $59.5 \mathrm{~g} \mathrm{U} / \mathrm{L}$ resin as the adsorbed uranium (VI) species to the tetravalent trisulfate species. In otherwords, it has been possible to achieve up to about $70 \%$ of the theoretical capacity under the determined optimum conditions. The achieved capacity has actually been found to be in agreement with the Langmuir isotherm and where the adsorption kinetic was found to obey the pseudo second order reaction. Concerning the effect of $\mathrm{Cl}^{-}$concentration, it was found that up to a $30 \mathrm{~g} / \mathrm{L}$ did not affect the adsorption capacity. Finally, the adsorbed uranium was found to be almost completely eluted by either $1 \mathrm{M} \mathrm{H}_{2} \mathrm{SO}_{4}$ or $0.6 \mathrm{M} \mathrm{Na}_{2} \mathrm{CO}_{3}$ solution.

\section{References}

[1] J. Choi, J.Y. Lee, J.S. Yang, Biosorption of heavy metals and uranium by starfish and Pseudomonas putida, Hazardous Materials, $15,2009,157-162$

[2] N.E. Belkhouche, M.A. Didi, D. Villemin, Separation of nickel and copper by solvent extraction using Di-2 ethylhexylphosphoric acid-based synergistic mixture, Solvent Extraction and Ion Exchange, 23, 2005, 677-693.

[3] A. Kadous, M.A. Didi, D. Villemin, Extraction of Uranium (VI) using D2EHPA/TOPO based Supported Liquid Membrane, Journal of Radioanalytical and Nuclear Chemistry, 280, 2009, 157-165.

[4] O. Abderrahim, M.A. Didi, D. Villemin, Polyethylenimine Methylenephosphonic Acid for the solid phase sorption of lead (II), Analytical Letters, 42, 2009, 1233-1244.

[5] P. Metilda, K. Sanghamitra, J.M. Gladis, G.R.K. Naidu, T.P. Rao, Amberlite XAD-4 functionalized with succinic acid for the solid phase extractive preconcentration and separation of uranium (VI), Talanta, 65, 2005, 192-200.

[6] R. Donat, G.K. Cilg1, S. Aytas, H. Cetisl, Thermodynamics Parameters and Sorption of U (VI) on ACSD, Radioanalytical and Nuclear Chemistry, 279, 2009, 271-280.

[7] M.E. Khalifa, Selective separation of uranium using Alizarin Red S (ARS)-modified anion exchange resin or by flotation of U-ARS chelate, Separation Science and Technology, 33, 1998, 2123-2141.

[8] A.M. Atta, Z.M. Abdel_Wahab, Z.A. El_Shafy, W.I. Zidan, Z.F. Akl, Uranyl ions uptake from aqueous solutions using crosslinked ionic copolymer based on 2-Acrylamide-2-methylpropane sulfonic acid copolymer, Journal of Dispersion Science and Technology, $31,2010,1606-1610$.

[9] A.M. Atta, A.A. Abdel_Rahman, I.E. Aassy, F.Y. Ahmed, M.F. Hamza, Adsorption properties of uranium on reactive crosslinked Acrylamidoxime and Acrylic acid copolymer resins, Journal of Dispersion Science and Technology, 32, 2011, 84-94.

[10] N. Saleem, H. Bhatti, Adsorption removal and recovery of uranium by citrus waste biomass, Bio Resources, 6, 2011, $2522-2538$.

[11] M . Karve, K. Pandey, Cyanex 272 impregnated on Amberlite XAD-2 for separation and preconcentration of U (VI) from uranmicrolite (leaches) ore tailings, Radioanalytical and Nuclear Chemistry, 285, 2010, 627-633.

[12] V.K. Jain, S.S. Sait, P. Shrivastav, Y.K. Agrawal, Sequential separation and trace enrichment of thorium and uranium on chelating resin Amberlite XAD-2-ortho-vanillinthiosemicarbazone (O-VTSC), Separation Science and Technology, 33, $1998,1803-1818$.

[13] W.A. Abbasi, M. Streat, Sorption of uranium from nitric acid solution using TBP-impregnated activated carbons, Solvent extraction and Ion exchange, 16, 1998, 1303-1320.

[14] G. Park, H.S. Park, S.I. Woo, Influence of $\mathrm{pH}$ on the adsorption of uranium ions by oxidized activated carbon and chitosan, Separation Science and Technology, 34, 1999, 833-854.

[15] K.A. Venkatesan, K.V. Shyamla, M.P. Antony, T.G. Srinivasan, P.R. Vasudeva, Batch and dynamic extraction of uranium from nitric acid medium by commercial phosphonic acid resin, Tulsion CH-96, Radioanalytical and Nuclear Chemistry, 275, 2008, 563-570.

[16] S.O. Aytas, S.A. Eral, Adsorption and thermodynamic behaviour of uranium in natural zeolite, Radoanalytical and Nuclear Chemistry, 260, 2004, 119-125.

[17] W. Zou, , L. Zhao, R. Han, Adsorption characteristics of uranyl ions by manganese oxide coated sand in batch mode, Radioanalytical and Nuclear Chemistry, 288, 2011, 239-249.

[18] M.A. Maheswari, M.S. Subramanian, Selective extraction of U (VI) and Th (IV) from high matrices using AXAD-16-BHBPD as a chelating polymeric matrix, Analytical Letters, 36, 2003, 2875-2892.

[19] D. Prabhakaran, M.S. Subramanian, Modified chloromethylated resin as an effective metal chelator in the extraction of U (VI) and Th (IV), Analytical Letters, 36, 2003, 2277-2289.

[20] B. Cyriac, B.K. Balaji, Anovel method od synthesizing solid phase adsorbent silica modified with Xylenol Orange: application for separation, preconcentraion and determination of uranium in calcium rich hydro-geochemical samples and sea water, Microchemica Acta, 171, 2010, 33-40.

[21] C.S. Raju, S. Srinivasan, M.S. Subramanian, New multi-dendate ion selevtive AXAD-16-MOPPA polymer for the preconcentration and sequential serparation of U (VI) and Th (IV) from rare earth matrix, Separation Science and Technology, 40, 2005, 2213-2230.

[22] N. Saleem, H. Bhatti, Adsorption removal and recovery of uranium by citrus waste biomass, Bio Resources, 6, 2011, 2522-2538.

[23] Z. Marczenko, M. Balcerzak, Separation, Preconcentration and Spectrophotometry in Inorganic Analysis. Elsevier Science B.V., Amsterdam the Netherlands, 2000, p.521.

[24] W. Davies, W. Gray, A rapid and specific volumetric method for the precise determination of uranium using ferrous sulfate as a reductant, Talanta, 11, 1964, 1203-1211.

[25] K.J. Mathew, B. Mason, M.E. Morales, U.I. Narayann, Uranium assay determination using Davies and Gray titration: An overview and implementation of GUM uncertainty evaluation, Radioanalytical and Nuclear Chemistry, 282, $2009,939-944$.

[26] L. Shapiro, W.W. Brannock, Rapid analysis of silicate, carbonate and phosphate rocks, U.S.Geol.Surv.Bull., 1144.A, 1962, 56.

[27] G. Wang, J. Liu, X. Wang, X. Chai, N. Deng, Adsorption of uranium (VI) from aqueous solution on calcined and acid-activated kaolin, Applied Clay Science, 47, 2010, 448-451.

[28] I. Langmuir, The adsorption of gases on plane surfaces of glass, mica and platinum, American Chemical Society, 40, 1918, 1361-1368.

[29] H. Freundlich, Adsorption in solution, Physical and Chemical Society, 40, 1906, 1361-1368.

[30] E. Metwally, Kinetic studies for sorption of some metal ions from aqueous acid solutions onto TDA impregnated resin, Radioanalytical and Nuclear Chemistry, 270, 2006, 559-566.

[31] A.Y. El-Nadi, A.J. Daoud, Sorption of uranium and thorium from sulfuric acid using TVEX-PHOR resin, Radioanalytical and Nuclear Chemistry, 265, 2005, 447-454. 